\title{
LARGE SCALE DEVELOPMENTS AND ONE HOUSE ZONING CONTROLS
}

\author{
Wiltiam Charney Vladeck*
}

All the literature concerning the development of the initial zoning ordinances and most of the literature in the two decades after the adoption of the first large scale zoning resolution in New York $\mathrm{City}^{1}$ in IgI6 is permeated with the concept of basic construction on a relatively small lot.

There is no reference to blocks, super-blocks or other nomenclature designating larger areas in any of the legislation or reports until quite recently. Even as of this date, the New York City Zoning Resolution defines a "lot," the "depth of a lot," and the "rear of a lot." The definition given to a lot is "a parcel or plot of ground which is or may be occupied by a building and accessory buildings including the open spaces required by this resolution."

By its own definition the resolution, by limiting the area of a lot to that occupied by a building, eliminates from most of the resolution any areas or parcels of land which contain more than one building and its accessory structures.

In actuality, this had been no great hardship. The general practice of construction was, until the middle Nineteen Thirties, almost entirely in the hands of private developers. Without the power of eminent domain, the acquisition of large areas was limited generally to outlying areas of communities where restrictions, if any, were of a minimal sort. Subdivision of the larger areas into small individual lots was the rule. The end result was that construction and development while done on a large scale and over large areas were, in so far as law was concerned, individual development of individual lots.

Traces of such subdivision, much of it premature, can still be found in such areas of urban centers which were not engulfed in the post-war building boom. The exceptions to this practice of subdividing into individual lots were almost exclusively devoted to large industrial developments which almost invariably were constructed in the more outlying areas.

Similarly, the few large residential developments which were planned as a unit also were out of the urban core so that they had the same latitude in so far as zoning restrictions were concerned as the non-residential uses.

The concepts of large scale developments, except as noted later, did not reach a point of general acceptance until the past two decades. The reasons are many

- Member of Joseph and Vladeck, architects, New York City; member American Institute of Architects.

1 The major portion of the following discussion is centered around practices and experiences in New York City. The rationale is, of course, the fact that the first zoning resolution was adopted in New York City and more large scale residential developments have been built there than in any other large urban center. 
and stem historically from building and financing techniques which had perhaps lived too long with the lot concept of planning and construction. The forerunners of large scale dwelling developments can be easily enumerated in the New York area and were mainly those where insurance companies or larger private building agencies began to conceive of erecting neighborhood developments as entities with homogeneous housing types and with direct relationship to community facilities. Excellent prototypes can be found in Sunnyside Gardens built in the late Nineteen Twenties by the City Housing Corporation in the Borough of Queens, New York; Radburn in New Jersey; and the Woodside apartment project in Queens, New York. Non-residential construction has fewer such examples in the urban center. The most outstanding was the development of Radio City as a commercial and amusement center.

Consciousness of the, difficulties of applying zoning ordinances based upon the individual lot concept to large scale developments of full blocks or superblocks, surrounded on all sides by public streets and with no actual side or rear property lines, actually took some time to develop. It was only after the beginnings of a national housing program had passed from the stage of direct federal ownership ${ }^{2}$ where no building or zoning laws were applicable, to the region of local ownership, where compliance with local regulations was mandatory, that the difficulties began to be actively recognized.

In point of time this occurred only in the years immediately preceding World War II and the attempts to catch up have not been successful.

The difficulties that were encountered by the designers of the initial and of even present day large scale developments can readily be understood. Almost inevitably the planners had been well indoctrinated in the technicalities of the zoning ordinance and while they instinctively planned to achieved conformity, anomalies between the basic concepts of zoning as a device to create proper environments in so far as light, air, and building bulk are concerned, and the narrow interpretations which develop with any form of restrictive legislation are quick to arise.

The majority of the problems arose where reconstruction or redevelopment of an inlying area, with its more restrictive zoning requirements, was predominantly residential. There has been relatively little difficulty with non-residential large scale development as yet.

The recognition of this conflict has grown slowly and, even today, full cognizance is still limited to the architects who have designed such developments on the one hand, and the administrative officials delegated to enforce zoning ordinances on the other.

It may be well to review some examples of such conflict and to point out the difficulties of zoning resolution revision.

${ }^{2}$ Under the PWA housing program of the mid-Thirties. 
II

Perhaps the major obstacles to such revisions of the zoning ordinance (other than the normal difficulties of amending technical laws) have been ( $x$ ) the general acceptance of the idea that most large scale developments have much higher standards of open space and consequently do not fill the permissible zoning envelopes; (2) the strong feeling on the part of many (particularly those engaged in the enforcement of the laws) that sooner or later the large developments will be broken down into individual lots; (3) the probability that with rare exception such problems will be encountered solely by public or quasi-public agencies; (4) the failure to realize that zoning is a tool that can be properly used only when there is understanding of the end to be achieved; and (5) the necessity of coordinating zoning resolution changes with other laws which also set bulk limits.

A.

The recognition of the higher standards of large scale developments can be found even in official documents, although there is the normal tendency to confuse "large scale" with "public." The history of most large scale developments to date has been almost entirely public or quasi-public for reasons which have been basically economic and which need not be developed further here. For example, the New York City Planning Commission in a report in 1944 stated:

It is a curious fact that the standards for public and semi-public housing are many times higher than those of private developments. The accompanying photographs show the striking differences in provisions for open space, light, air and recreation in such projects as compared to private ones.

It is interesting to note that the photographs to which this statement refers show three different types of large scale residential developments. The first is the stateaided public low rent Fort Greene Houses, Brooklyn, New York, built by the New York City Housing Authority; the second, a Redevelopment Companies Act project for which the city used its own power of eminent domain, Stuyvesant Town, Manhattan, New York, built by the Metropolitan Life Insurance Company; and the third, a purely private large scale venture, also built by the Metropolitan Life Insurance Co., Parkchester, Bronx, New York.

It is to be hoped that this identification of large scale developments with public or semi-public housing will vanish, but this is not likely where such developments are located in inlying areas in our large urban centers. Parkchester could be a purely private venture because of the ability of the owner to acquire a large vacant tract, but both Stuyvesant Town and Fort Greene had to depend upon public help in so far as both land acquisition and change in street pattern were concerned. It is obvious that without some form of governmental assistance in assembling land through the power of eminent domain, and in permitting changes in existing street patterns, few, if any, private developers can get title, or use sizable inlying areas which are now vested in a multiplicity of owners. 
Despite the fact that developments of this sort, both private and public, generally do not approach the maximum permitted land coverages and heights, difficulties are encountered in the execution of the projects. A case in point can well be the experience of planning Lillian Wald Houses, a state-aided, low rent public housing project built by the New York City Housing Authority in the lower east side of Manhattan, the historic slum area of New York.

In 1945, the architects, who were retained by the New York City Housing Authority for the design of the development, filed plans with the Department of Housing and Buildings. ${ }^{3}$

${ }^{3}$ The municipal agency designated by the city charter to supervise and enforce the Administrative (Building) Code, the Multiple Dwelling Law (a state law applicable then only to New York City, now also applicable to the City of Buffalo), and the Zoning Resolution.

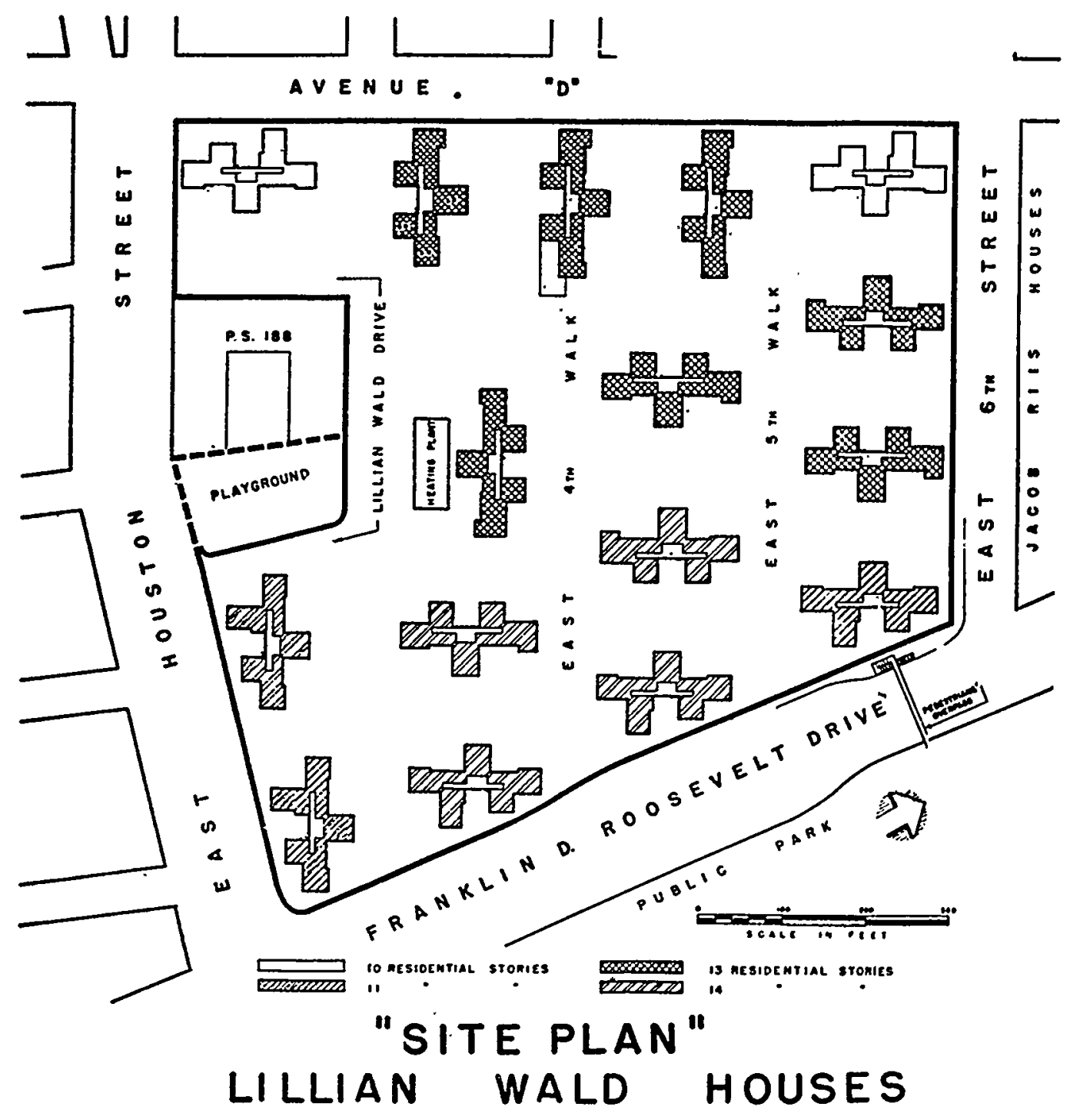


Included among the plans filed was a site plan which showed, among other things, the locations of the buildings, their distances from the building (property) lines and from each other, the heights of the structures, etc. The diagrammatic plan reproduced herein represents a building bulk appreciably below the normal standards of buildings which have been and still are being erected in New York City.

Despite the relative openness of the plan, however, and the fact that the total areas of all floors of all buildings were less than twice the site area, the first objection by the Department of Housing and Buildings reads as follows:

A-r Indicate on "site plan" compliance with the provisions of Sections 8 and 9 of Article III of the Zoning Resolution as amended on December I944.

The proposed method of computing "dormers" above the required setback is not acceptable and is not in conformity with the provisions of Subdivision (c) of Section 9 of Article III of the Zoning Resolution which is interpreted by the Department of Housing and Buildings, under G.O. $7 \mathrm{I}$ of 1945 , as follows:

"The references to "6o percent of the length of such frontage of such part of the buildings' and 'such frontage length of such structure at any given level' refer to lengths of the building proper at various levels and NOT TO THE FRONTAGE LENGTH OF THE LOT OR PLOT. 'DORMER AND BULKHEAD PRIVILEGES SHALL BE BASED SOLELY AND ONLY AS TO LENGTH ON THE BASIS OF THE FRONTAGE LENGTH OF THE STRUC'TURE AT THE LEVEL INVOLVED'”.

During a number of discussions with the examiners of the Department of Housing and Buildings where the architects vainly attempted to show that the proposed plan was in full accord with the spirit of the premise upon which the zoning resolution was created, it was brought out that if all the building wings were connected by structures as shown herein, ${ }^{4}$ there would be full compliance with the letter of the resolution.

This indicates how the increase of bulk and consequently of population density by the increase in size or number of buildings could have put the development in compliance with the zoning resolution.

Obviously the zoning resolution techniques had become technical formulae rather than an attempt to interpret the resolution in order to comply with its original purpose and spirit.

Such technical conformity was agreed to, but short of redesigning to a greater bulk and a greater density by connecting the structures or by moving the structures about and creating a new site plan, or by further widening already widened streets, no approval would be granted. It is important to be aware that this action was not an arbitrary opinion of an individual examiner but was a departmental decision arrived at by the top officials of the Department up to and including the Commissioner.

The only recourse of the architects was to file an appeal with the Board of Standards and Appeals. Such appeal was filed and, after hearing and deliberation, the following decision was announced.

\footnotetext{
"This plan was never actually submtted to the Department of Housing and Buildings but is included as an example of how technical conformity could create less desirable results.
} 
WHEREAS the applicant states that the premises consist of a plot of $96 \mathrm{r}^{\prime}$ and $6 \times 3^{\prime}$ front by $937^{\prime}$ and $865^{\prime}$ in depth on which it is proposed to erect 13 buildings, 14 stories in height, and 3 buildings, Io stories in height, of Class I construction; that it is proposed to demolish existing building and erect Class A multiple dwellings and

WHEREAS the applicant contends that the proposed project will consist of four II story and twelve $\mathrm{I}_{4}$ story buildings on a net area of $70 \mathrm{r}, 768 \mathrm{sq}$. $\mathrm{ft}$.; that the land area to be covered by all the buildings will be 125,869 sq. $\mathrm{ft}$. or approximately $\mathrm{r} 8 \%$ of the entire net area of the project; that it is apparent, therefore, that the ratio of the area of the buildings to the area of the site is considerably less than the maximum of $25 \%$ set forth in the zoning resolution; that the plan as presented provides adequate light and air in all respects as evidenced by the minimum distance between any two buildings.

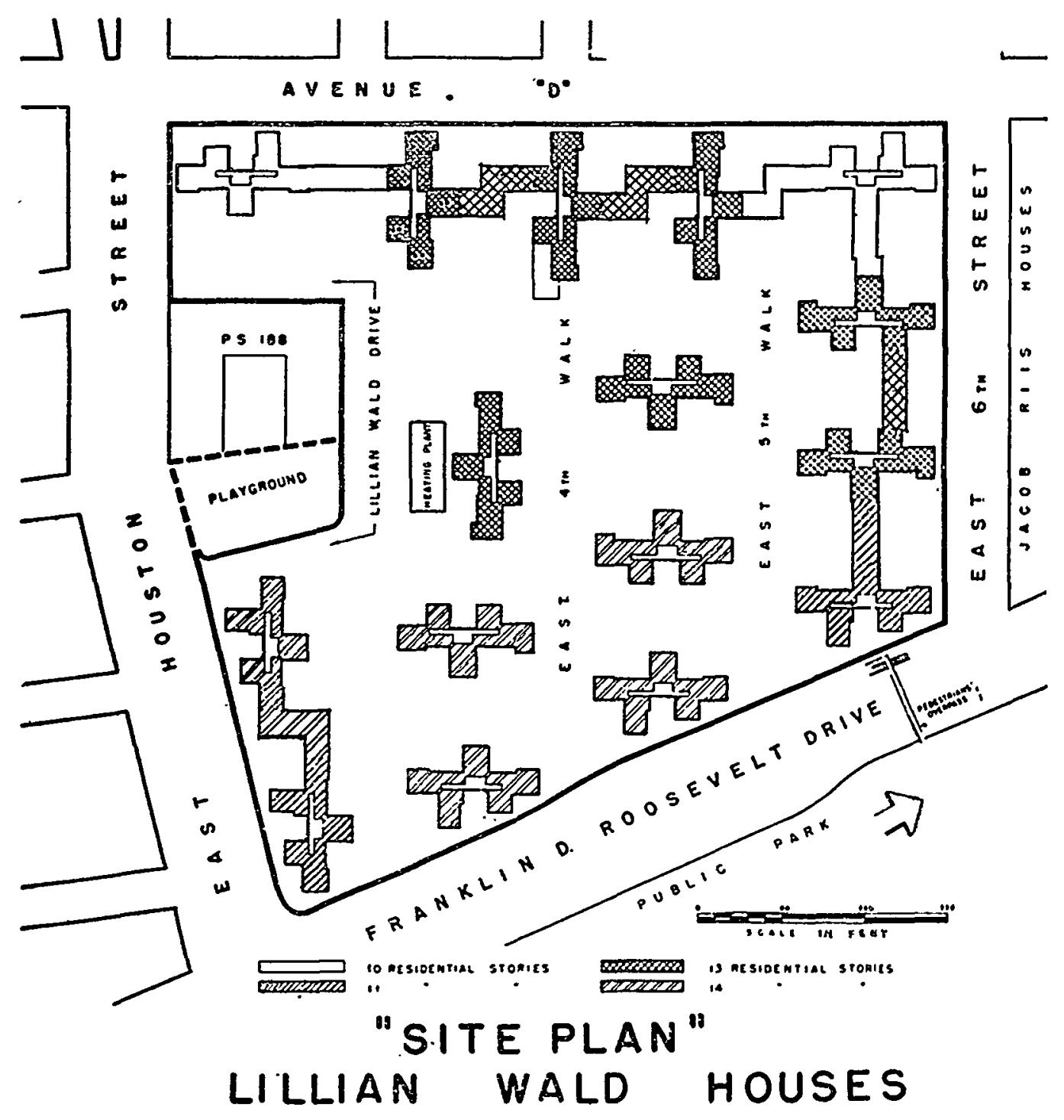


RESOLVED that the Board of Standards and Appeals does hereby make a variation in the application of the area district requirements of the zoning resolution and that the application be and it hereby is granted under Section $2 I$ thereof, as to N.B. application $56,57,58,64$ of $x 945$ on condition that in all other respects the height requirements of the zoning resolution shall be complied with; that all permits shall be obtained and all work completed within one year from date of this resolution.

B.

The anticipation of eventual sale and split up into individual ownerships of large scale developments is not uncommon, and even at this rather early stage in the history of such developments there are a few examples of reversion to the lot base which justify this attitude. In addition to this type of change, there are also cases of sales of property erected by the Federal Government without direct adherence to local zoning ordinances to local agencies or individuals, who then face the difficult problem of demonstrating compliance in order to get certificates of occupancy.

A good example of this breakdown can be found in the recent history of Sunnyside Gardens. In the original development built in the late Twenties, there were three central garage compounds providing service to the adjacent owners. The original building company and its successors held title to the garages despite the fact that the houses (two story row houses) were sold on an individual basis. When the company owning one of the garage compounds finally sold it to a corporation formed by 26 owners of houses and that corporation in turn deeded the garages separately to 26 individual owners, problems immediately arose. As a compound they had been recognized as an accessory to a residential use, but now the area is zoned residential and a garage covering the entire area of a lot less than Io by 20 feet is not interpreted as being an accessory use, despite the fact that the use is the same, and by the same people.

It has now become necessary for the new owners, each individually, to re-file plans with and get objections from the Department of Housing and Buildings and then to throw themselves upon the mercy of the Board of Standards and Appeals in order to continue legally a use which has existed for almost three decades without change.

Certainly the basic intent of providing accessory parking use still is valid, but technically the tool of zoning now would not permit such similar use without grave difficulties. Changes in the zoning resolution to retain the intent of accessory parking within reasonable walking distance of dwellings should eliminate the requirement that such use must be on the same lot.

An indication of the attitude of the examining officials toward such a possible breakdown can be found in almost every large scale development which has been or is being planned in New York City. It is necessary, in filing such plans, to indicate initially the individual lot lines of each separate structure. These lines do 
not exist in actuality, but are rather projections in order to permit examination of compliance on the basis of individual buildings on individual lots as shown herein.

There is no other machinery in the zoning resolution or building code, as a matter of right, which permits examination of large scale developments without the necessity of going originally to the Board of Standards and Appeals. Section 2I-C of the New York City Zoning Resolution provides this method of approval, but in practice, it is much simpler to draw the lines than to have to spend the time and energy required to go to another reviewing board.

c.

The argument that such problems will be met only by public or quasi-public agencies who have the time and personnel to go all around Robin Hood's barn in order to get approval is erroneous for at least two reasons. On the one hand, it is

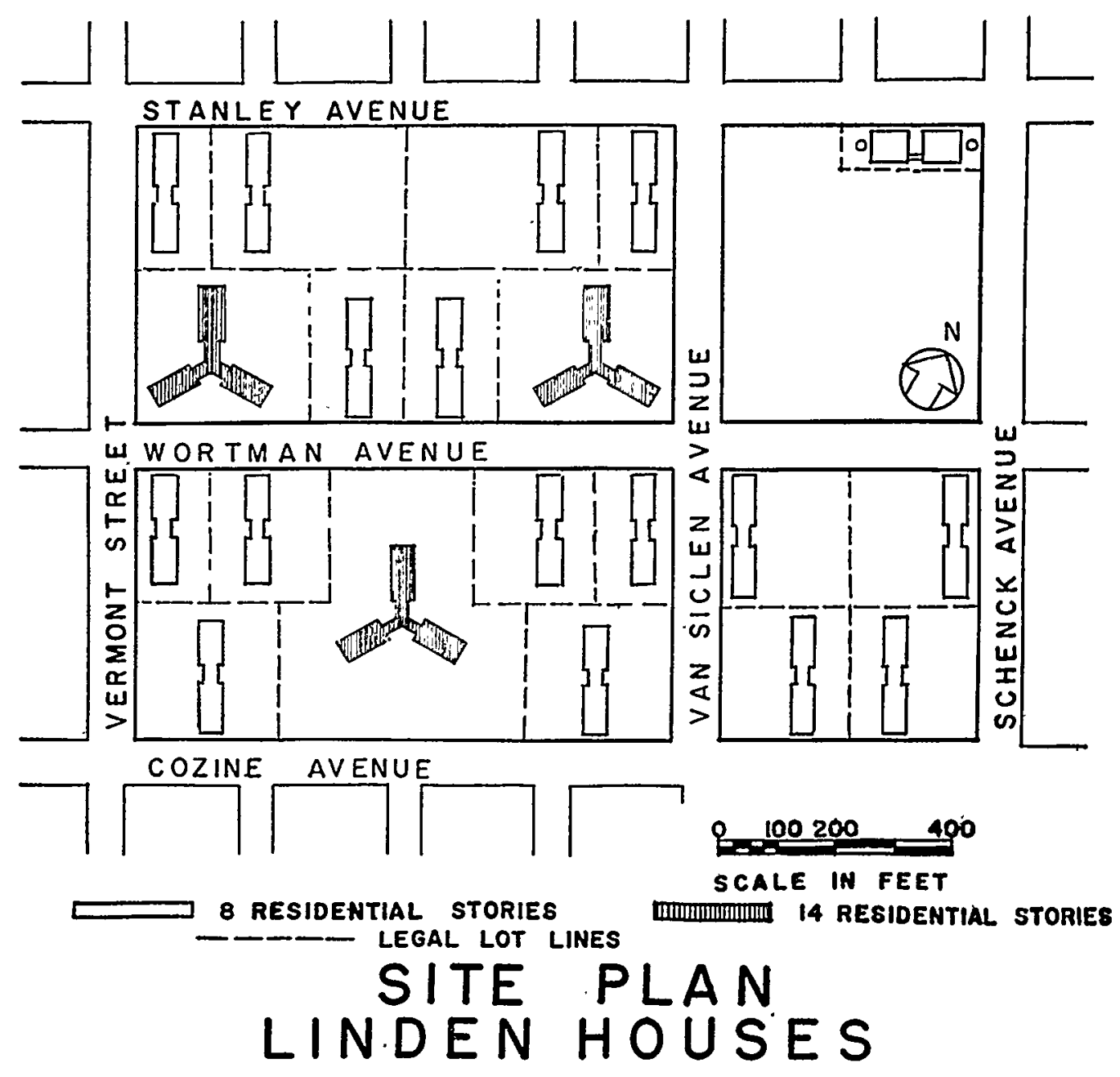


certainly not good governmental procedure to make difficulties for anyone, be they public or private. On the other hand, the work of obtaining initial approvals falls in most part upon private architects and engineers retained by such agencies. The increasing number of large private developments brings the problem into sharper focus. The ultimate breakup of large developments can be anticipated, but it certainly could be done more simply.

The chief difficulty in obtaining amendment of the zoning resolution is, I believe, the fact that it still affects relatively few people and they are in the main technicians who are presumed to be competent to handle the extra work entailed, even though it be unnecessary. Certainly almost all large developments have been and will continue to be under the maximum bulk standards now permitted under the zoning laws. The revisions which might make approvals simpler and permit technical compliance with the spirit of the law as a matter of right need not create lower bulk or density requirements of themselves.

D.

There have been amendments to zoning and to planning regulations adopted in the past and there are many proposed, but few achieve a clear statement of intent which provides an adequate basis for direct appraisal or review.

There are three basic zoning regulations already enacted in the New York City Code: Section 3(ro) applicable to non-residential uses on plots of ro acres or more in areas zoned residential; Section rg-B (a) which permits lower initial parking spaces for public housing projects fully subsidized from federal, state or city sources; and Section 2I-C mentioned previously. None of these helps much in the initial design of projects.

Zoning is, after all, a tool which a municipality or other governing agency uses to effectuate a plan. Much of the difficulty in meeting present zoning requirements stems from the basic fact that most communities have no plan advanced to such a point that it clearly guides growth or rebuilding, and have no clear concept of all the basic reasons for zoning. Moreover, there is both lack of coordination between a Master Plan (where it does exist) and the Zoning Resolution, and also the disappearance from too many minds of the basic concepts of the original zoning and its yard, setback, height, etc. requirements.

A great deal of interesting comment was engendered during and preceding hearings held on a new zoning proposal which had been prepared by a firm of consultants $^{5}$ for the New York City Planning Commission a few years ago. The general tenor of many presentations was to the effect that the proposed zoning resolution was in actuality a master plan. Nothing could have been further from the truth. The proposal was simply an attempt to provide a better tool for the effectua-

\footnotetext{
¿ Pian for Rezoning the City of New York, A Report Submitted to the City Planning Commission by Harrison, BaLlard, and Allen (Oct. I950).
} 
tion of such a master plan as had been or would be adopted. The fact that the proposal is still unaccepted by the City Planning Commission or by all too many of the public stems to a great extent, I believe, from such misunderstanding.

E.

There has been a good deal of discussion about the necessity in new zoning regulations, not only for provisions for the reduction of presently permitted building bulk, but also for provisions making certain in advance that adequate spaces are set aside for community uses when large scale projects are developed.

Many smaller urban centers and semi-urban communities do have such requirements in their zoning or, more generally, in their sub-division regulations; still it may be questionable as to how far a larger city should go where undeveloped land is concerned. Where rebuilding existing areas is done on a large scale, however, the solution becomes somewhat simpler. Any large development in an urban center invariably requires the closing of city streets and it should not be considered inequitable to require the earmarking of an area, more or less equivalent, for community purposes such as street widening, parks, playgrounds, school sites, etc. In practice this has been the case to a large extent in most large scale developments, not as a matter of law, or of zoning, but as a quid pro quo in obtaining approvals from the regulatory agencies. With the growth of large scale developments and the hope of an ever increasing number of such developments-public, quasi-public, and private-a method of setting legal requirements for such property reservations must ultimately be adopted. There is no method of making such provision, short of the completion of a master plan for every community, which would be easily workable, except a general clause in a zoning resolution. This clause would be to the effect that the developer would be required to cede to the municipality such areas as would be required for public uses, up to the extent of the area received by the developer from the closing of streets, with additional public areas, if required, to be acquired by the municipality simultaneously at a fair price.

III

Proposed revisions of zoning resolutions, therefore, should be developed with the background reasoning that:

I. The concepts of bulk, light, and air must be re-examined in connection with large scale developments.

2. Accepted standards of large scale design are much higher, in so far as density, coverage, bulk are concerned, than lot zoning requirements.

3. There should be a provision in the zoning law that future changes of ownership would not require adherence to individual lot requirements if no substantive change in structures or uses is made. 
4. There should be a mandatory requirement in the law that certain public spaces be a necessary adjunct to any large scale development.

5. Changes in zoning laws are difficult to achieve at best, and special efforts are required when the effect of changes is applicable to what is still a basically governmentally sponsored or aided operation.

6. The best results require the best tools, and present inadequacies in zoning codes do not permit easy attainment of these results.

7. Large scale developments and large scale redevelopment must be encouraged and assisted if we hope ever to rebuild our cities. 